\title{
Critical choices in predicting stone wool biodurability: lysosomal fluid compositions and binder effects
}

Ursula G. Sauer, Kai Werle, Hubert Waindok, Sabine Hirth, Oliver Hachmöller, Wendel Wohlleben*

SI_1: Table - Physical-chemical properties of the MMVFs

SI_2: Table - Oxide composition of the MMVF products (\%)

SI_3: Table - Thermogravimetric analysis

SI_4: Binder characterization

SI_5: Figure - Chemical composition of the MMVF_UK_1 surface layer by XPS with line shape analysis

SI_6: Figure - Pyrolysis GC-MS chromatogram of MMVF_UK_1, MMVF_UK_5, and MMVF_UK_10

SI_7: Table - Peak identification of components in pyrolysis GC/MS chromatogram

SI_8: Figure - Set up of the dissolution experiments

SI_9: Figure - Dissolution kinetics, exemplary results in the pH 4.5 PSF medium

SI_10: Figure - Additional SEM results of fibers as received, and after pH 4.5 PSF dissolution testing

SI_11: Figure - Binder coverage on the MMVF_UK_1 fiber surface, detected by SIMS mappings 


\section{SI_1: Physical-chemical properties of the MMVF products}

Table SI_1 Physical-chemical properties of the MMVF products

\begin{tabular}{|l|c|c|c|c|c|c|c|c|}
\hline & Unit & $\begin{array}{c}\text { MMVF_- } \\
\text { UK_1 }\end{array}$ & $\begin{array}{c}\text { MMVF_ } \\
\text { UK_2 }\end{array}$ & $\begin{array}{c}\text { MMVF_ } \\
\text { UK_5 }\end{array}$ & $\begin{array}{c}\text { MMVF_ } \\
\text { UK_6 }\end{array}$ & $\begin{array}{c}\text { MMVF_ } \\
\text { UK_9 }\end{array}$ & $\begin{array}{c}\text { MMVF_ } \\
\text { UK_10 }\end{array}$ & $\begin{array}{c}\text { MMVF_ } \\
\text { DK_5 }\end{array}$ \\
\hline Fiber diameter & $\mu \mathrm{m}$ & $0.5-20$ & $2.0-24$ & $1.5-15$ & $1.5-20$ & $2.5-20$ & $1.0-25$ & $0.3-20$ \\
\hline $\mathrm{BET}$ & $\mathrm{m}^{2} / \mathrm{g}$ & 0.22 & 0.28 & 0.22 & 0.24 & 0.61 & 0.51 & 0.22 \\
\hline$\Sigma \mathrm{CaO}+\mathrm{MgO}$ & $\%$ & 31.5 & 31.4 & 31.5 & 31.7 & 31.2 & 32.1 & 27.7 \\
\hline$\Sigma \mathrm{Na}_{2} \mathrm{O}+\mathrm{K}_{2} \mathrm{O}$ & $\%$ & 2.4 & 2.4 & 2.3 & 2.3 & 2.2 & 2.3 & 2.6 \\
\hline $\begin{array}{l}\mathrm{A} \mathrm{l} /(\mathrm{Si}+\mathrm{Al}) \\
\text { atomic ratio }\end{array}$ & $\begin{array}{c}\text { none) } \\
0.34\end{array}$ & 0.34 & 0.35 & 0.34 & 0.34 & 0.34 & 0.33 \\
\hline $\begin{array}{l}\mathrm{Binder} \text { content } \\
\text { [a] }\end{array}$ & $\%$ & 2.1 & 2.3 & 3.1 & 2.6 & 2.9 & 2.0 & 2.2 \\
\hline
\end{tabular}

[a] all TGA mass loss to $800{ }^{\circ} \mathrm{C}$

The materials with intermittent numbering were also analyzed. MMVF_UK_4, MMVF_UK_7, MMVF_UK_8 remained within the compositional range of the other UK-sampled products. MMVF_UK_3 was a specialty pipe-shaped, mechanically solid sleeve of complex organic and inorganic composition that was incomparable. MMVF_DK_5 differentiates significantly in oxide composition by reduced $\mathrm{TiO}_{2} \mathrm{Na}_{2} \mathrm{O}$ and $\mathrm{CaO}$ content, leading to a lower $\mathrm{KI}$ index while keeping the $\mathrm{Al} /(\mathrm{Si}+\mathrm{Al})$ atomic ratio at the same level.

Fiber diameter is given as indicative value determined from SEM images with $30 \mu \mathrm{m}$ field of view. 


\section{SI_2: Oxide composition of the MMVF products (\%)}

Table SI_2 Oxide composition of the MMVF products (\%)

\begin{tabular}{|l|l|l|l|l|l|l|l|}
\hline & $\begin{array}{l}\text { MMVF_ } \\
\text { UK_1 }\end{array}$ & $\begin{array}{l}\text { MMVF_ } \\
\text { UK_2 }\end{array}$ & $\begin{array}{l}\text { MMVF_ } \\
\text { UK_5 }\end{array}$ & $\begin{array}{l}\text { MMVF_ } \\
\text { UK_6 }\end{array}$ & $\begin{array}{l}\text { MMVF_ } \\
\text { UK_9 }\end{array}$ & $\begin{array}{l}\text { MMVF_ } \\
\text { UK_10 }\end{array}$ & $\begin{array}{l}\text { MMVF_ } \\
\text { DK_5 }\end{array}$ \\
\hline A12O3 & $\mathbf{1 8 . 5}$ & $\mathbf{1 9 . 1}$ & $\mathbf{1 8 . 9}$ & $\mathbf{1 8 . 9}$ & $\mathbf{1 8 . 3}$ & $\mathbf{1 8 . 9}$ & $\mathbf{1 8 . 2}$ \\
\hline $\mathrm{B} 2 \mathrm{O} 3$ & 0.0 & 0.0 & 0.0 & 0.0 & 0.0 & 0.1 & 0.0 \\
\hline $\mathrm{BaO}$ & 0.0 & 0.1 & 0.1 & 0.1 & 0.0 & 0.1 & 0.03 \\
\hline $\mathrm{CaO}$ & $\mathbf{2 2 . 7}$ & $\mathbf{2 2 . 8}$ & $\mathbf{2 2 . 2}$ & $\mathbf{2 2 . 4}$ & $\mathbf{2 2 . 5}$ & $\mathbf{2 2 . 7}$ & $\mathbf{1 9 . 2}$ \\
\hline $\mathrm{Cr} 2 \mathrm{O} 3$ & 0.0 & 0.0 & 0.0 & 0.0 & 0.0 & 0.0 & 0.09 \\
\hline Fe2O3 & 8.0 & 7.1 & 7.6 & 7.7 & 7.7 & 8.3 & 7.3 \\
\hline $\mathrm{K} 2 \mathrm{O}$ & 0.4 & 0.4 & 0.4 & 0.4 & 0.4 & 0.4 & 0.4 \\
\hline $\mathrm{MnO}$ & 0.3 & 0.3 & 0.4 & 0.4 & 0.4 & 0.4 & 0.49 \\
\hline $\mathrm{MgO}$ & $\mathbf{8 . 8}$ & $\mathbf{8 . 6}$ & $\mathbf{9 . 3}$ & $\mathbf{9 . 3}$ & $\mathbf{8 . 6}$ & $\mathbf{9 . 5}$ & $\mathbf{8 . 5}$ \\
\hline Na2O & $\mathbf{2 . 0}$ & $\mathbf{2 . 0}$ & $\mathbf{1 . 9}$ & $\mathbf{1 . 9}$ & $\mathbf{1 . 9}$ & $\mathbf{1 . 9}$ & $\mathbf{2 . 2}$ \\
\hline $\mathrm{P} 2 \mathrm{O} 5$ & 0.1 & 0.1 & 0.1 & 0.2 & 0.1 & 0.2 & 0.15 \\
\hline $\mathrm{S}$ & 0.1 & 0.2 & 0.2 & 0.2 & 0.1 & 0.1 & 0.02 \\
\hline SiO2 & $\mathbf{4 1 . 3}$ & $\mathbf{4 1 . 3}$ & $\mathbf{3 9 . 6}$ & $\mathbf{4 1 . 7}$ & $\mathbf{4 0 . 0}$ & $\mathbf{4 1 . 7}$ & $\mathbf{4 1 . 8}$ \\
\hline $\mathrm{SrO}$ & 0.0 & 0.0 & 0.0 & 0.0 & 0.0 & 0.0 & 0.06 \\
\hline TiO2 & $\mathbf{1 . 2}$ & $\mathbf{1 . 3}$ & $\mathbf{1 . 3}$ & $\mathbf{1 . 2}$ & $\mathbf{1 . 2}$ & $\mathbf{1 . 2}$ & $\mathbf{0 . 7 0}$ \\
\hline
\end{tabular}

The oxide composition demonstrates a much smaller variation of oxides across the test set than the earlier test set, which had been collected from several different countries (Wohlleben et al. 2017). Not only the oxides of Si and Al, that are most important for the regulatory exoneration from carcinogenicity classification following Nota Q in Annex VI, Section 1.1.2.3 of the EU Classification and Labelling Regulation (EP and Council 2008), but also the oxides of Ca, Fe, $\mathrm{Mg}$ and the traces of oxides of $\mathrm{K}, \mathrm{Ba}, \mathrm{Mn}, \mathrm{Na}, \mathrm{Ti}$ are identical within $10 \%$ of the average. $\mathrm{CaO}$ is identical within $0.2 \%$ in the UK series, but $3 \%$ lower in the MMVF_DK_5. $\mathrm{Al}_{2} \mathrm{O}_{3}$ is identical within $0.4 \%$, indicating a highly consistent core fiber composition that is just within the limit of the exonerated chemical compositional range of 18 to $24 \% \mathrm{Al}_{2} \mathrm{O}_{3}$.

\section{References}

Regulation (EC) No 1272/2008 of the European Parliament and of the Council of 16 December 2008 on classification, labelling and packaging of substances and mixtures, amending and repealing Directives 67/548/EEC and 1999/45/EC, and amending Regulation (EC) No 1907/2006. OJ L 353, 31 December 2008, p. 1-1355.

Wohlleben, W., Waindok, H., Daumann, B., Werle, K., Drum, M., and Egenolf, H. (2017) Composition, respirable fraction and dissolution rate of 24 stone wool MMVF with their binder. Part. Fibre Toxicol. 14(1), 29. 
SI_3: Thermogravimetric analysis

Table SI_3 Thermogravimetric analysis

\begin{tabular}{|l|l|l|l|l|l|l|l|l|}
\hline & $\begin{array}{l}\text { Mass change } \\
\text { up to } 330^{\circ} \mathrm{C}\end{array}$ & $\begin{array}{l}\text { Mass change } \\
\text { of main peak }\end{array}$ & $\begin{array}{l}\text { Range } \\
(\mathrm{min})\end{array}$ & $\begin{array}{l}\text { Range } \\
(\mathrm{max})\end{array}$ & $\begin{array}{l}\text { Peak } \\
(\mathrm{DSC})\end{array}$ & $\begin{array}{l}\text { Mass change } \\
530^{\circ} \mathrm{C} \text { to } \\
800^{\circ} \mathrm{C}\end{array}$ & $\begin{array}{l}\text { Total } \\
\text { mass } \\
\text { loss }\end{array}$ \\
\hline UK_1 & $-0.8 \%$ & $-1.3 \%$ & 330 & 496 & 434.2 & $0.7 \%$ & \\
\hline UK_2 & $-0.7 \%$ & $-1.6 \%$ & 330 & 496 & 448.8 & $0.7 \%$ & $-2.1 \%$ \\
\hline UK_4 & $-0.6 \%$ & $-1.2 \%$ & 330 & 496 & 438.3 & $1.0 \%$ & $-2.3 \%$ \\
\hline UK_5 & $-0.7 \%$ & $-2.4 \%$ & 330 & 516 & 460.1 & $0.8 \%$ & $-1.8 \%$ \\
\hline UK_6 & $-0.4 \%$ & $-2.2 \%$ & 330 & 538 & 450.0 & $0.7 \%$ & $-3.1 \%$ \\
\hline UK_7 & $-0.7 \%$ & $-1.5 \%$ & 330 & 530 & 449.6 & $0.7 \%$ & $-2.6 \%$ \\
\hline UK_8 & $-0.9 \%$ & $-1.6 \%$ & 330 & 530 & 450.6 & $0.7 \%$ & $-2.2 \%$ \\
\hline UK_9 & $-1.0 \%$ & $-1.9 \%$ & 330 & 530 & 450.0 & $0.7 \%$ & $-2.5 \%$ \\
\hline UK_10 & $-0.6 \%$ & $-1.4 \%$ & 330 & 530 & 444.9 & $0.8 \%$ & $-2.9 \%$ \\
\hline DK_5 & $-0.7 \%$ & $-1.5 \%$ & 307 & 512 & 431.2 & $0.4 \%$ & $-2.0 \%$ \\
\hline
\end{tabular}

The position of the main peak, and the associated mass loss, are very similar for all tested materials. Only MMVF_UK_3 was excluded due to a much more complex, endo- and exothermal degradation pattern. 


\section{SI_4: Additional binder characterization}

Binder was analyzed (Figure SI_5, Table SI_7) on an Analytix CDS Pyroprobe 6200 with the valve of the oven and the transfer line operating at $325^{\circ} \mathrm{C}$, ramped by $20^{\circ} \mathrm{C}$ per second up to a final $750^{\circ} \mathrm{C}$, holding for 30 seconds. The pyrolysis products were analyzed on a Perkin Elmer Clarus $500 \mathrm{GC} / \mathrm{MS}$ with the following conditions:

- Column Restek Rxi-5Sil MS (30m x 0.25mm x 0.25um)

- Injector Temp: 280oC

- Carrier Gas: Helium

- $\quad$ Split Ratio: 50

- $\quad$ Flow Rate: $1 \mathrm{~mL} / \mathrm{minute}$

- $\quad$ Temperature Programme: Isothermal at $40 \circ \mathrm{C}$ for 2 minutes

- Ramp from $40 \mathrm{oC}$ to $320 \mathrm{oC}$ at $10 \mathrm{oC} /$ minute

- Isothermal at $3200 \mathrm{C}$ for 15 minutes

Peak identities were obtained by interrogation of the respective mass spectrum (Figure SI_5) and comparison to reference spectra. Only peaks clearly visible in sample chromatogram are included in the results table (Table SI_7). 
SI_5: Chemical composition of the MMVF_UK_1 surface layer by x-ray photoelectron spectroscopy (XPS) with line shape analysis

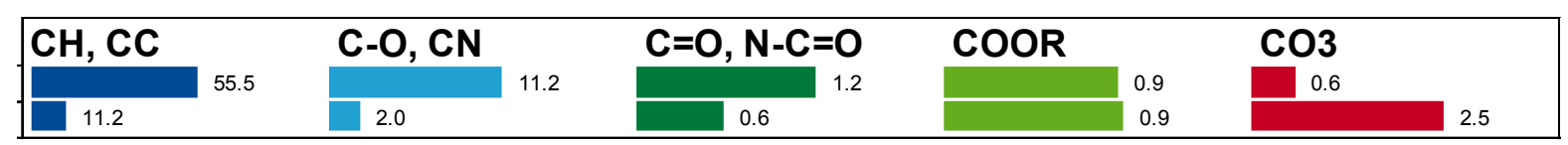

\begin{tabular}{|c|c|}
\hline Silan & Siloxan \\
\hline 0.8 & 2.2 \\
\hline
\end{tabular}

\begin{tabular}{|lcc|}
\hline Imin & Amin, Amid & prot. Amin, prot. Amid \\
& 0.8 & \\
& & \\
\hline
\end{tabular}
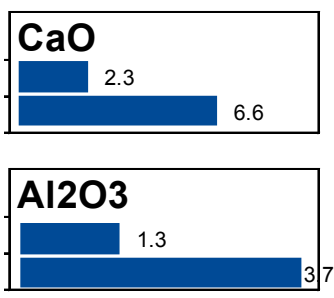

Figure SI_5 Chemical composition of the MMVF_UK_1 surface layer by X-ray Photoelectron Spectroscopy (XPS) with line shape analysis.

For each element, the upper row reports the material as-received, and the lower row the material after binder removal. The XPS analyses used a Versa Probe 5000 (Physical Electronics, USA) spectrometer using monochromatic Al Ka radiation $(\mathrm{h} v=1486.6 \mathrm{eV})$ at a base pressure of $1.5^{*} 10^{7} \mathrm{~Pa}$ on an area of $100 \times 1400 \mu \mathrm{m}^{2}$. The built-in charge neutralizer system was used on all specimens. To minimize the effects of differential charging, all samples were mounted insulated against ground. Survey scan analyses were carried out at a pass energy of $117 \mathrm{eV}$ and an energy step size of $0.5 \mathrm{eV}$. High resolution analyses were carried out on the same analysis area with a pass energy of $23.5 \mathrm{eV}$ and an energy step size of $0.1 \mathrm{eV}$. All samples have been measured on three different non-overlapping locations to obtain information about their homogeneity. Resulting survey and detail spectra were analyzed using CasaXPS software version 2.3.22PR1.0 using Shirley background subtraction for all peaks. 
SI_6: Pyrolysis GC-MS chromatogram of a) MMVF_UK_5; b) MMVF_UK_1; c) MMVF_UK_10

a)

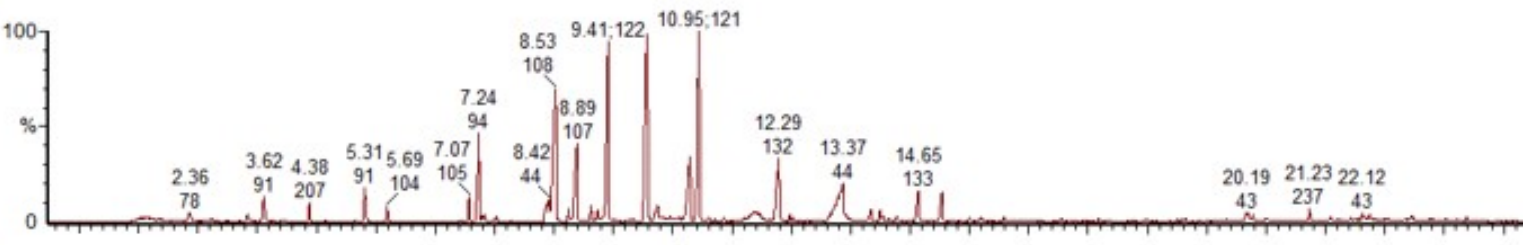

b)

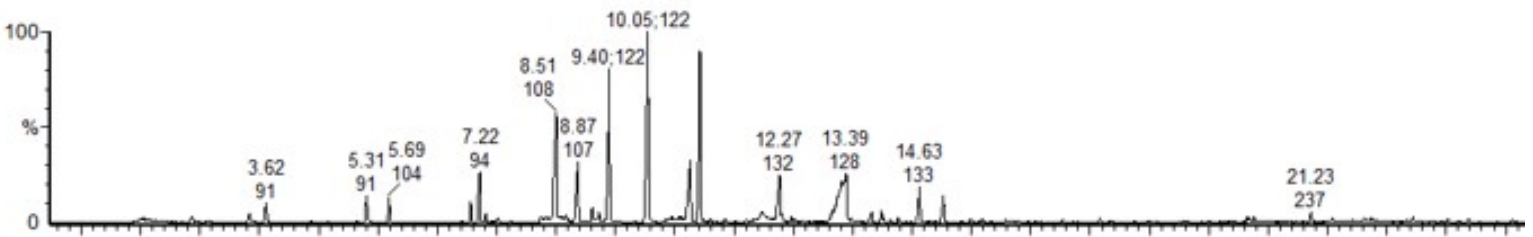

c)

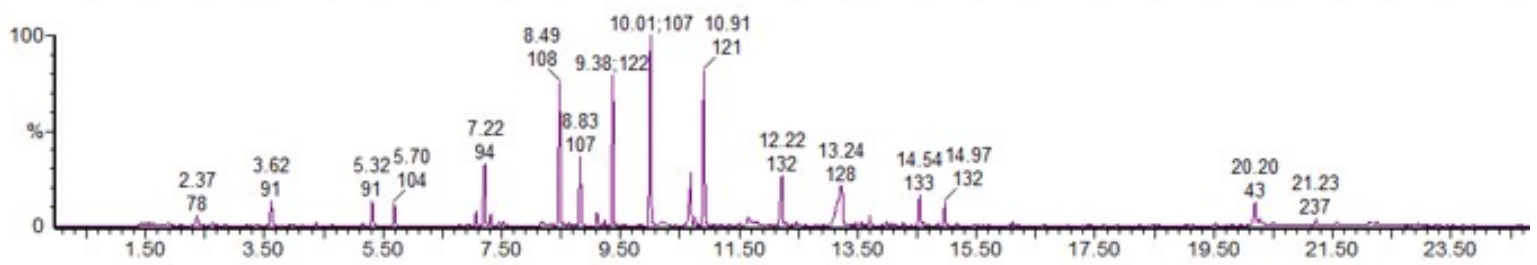

Figure SI_6: Pyrolysis GC-MS chromatogram of a) MMVF_UK_5; b) MMVF_UK_1; c) MMVF_UK_10.

Times shown are in minutes. The MMVFs are tested for binder effects on dissolution (Figures 1 and 2, Tables 3 and 4 in main manuscript). 
SI_7: Peak identification of components in pyrolysis GC/MS chromatogram

\begin{tabular}{|l|l|}
\hline Time / minutes & Identification \\
\hline $1.30-2.20$ & amines \\
\hline 2.36 & benzene \\
\hline 3.33 & dimethyl amino acetonitrile \\
\hline 3.62 & toluene \\
\hline 5.31 & xylene \\
\hline 5.69 & styrene \\
\hline 7.06 & trimethyl benzene \\
\hline $\mathbf{7 . 2 2}$ & phenol \\
\hline 7.32 & benzonitrile \\
\hline 7.53 & benzofuran \\
\hline $\mathbf{8 . 2 5}$ & dimethyl urea \\
\hline $\mathbf{8 . 5 1}$ & methyl phenol \\
\hline $\mathbf{8 . 8 7}$ & methyl phenol \\
\hline $\mathbf{9 . 4 0}$ & dimethyl phenol \\
\hline 10.05 & dimethyl phenol \\
\hline $\mathbf{1 0 . 7 7}$ & toluene isocyanate \\
\hline 10.91 & trimethyl phenol \\
\hline $\mathbf{1 2 . 2 7}$ & dimethyl phenyl isocyanate \\
\hline 13.39 & possible pyridine related compound \\
\hline 13.82 & hydroxy benzonitrile \\
\hline 13.99 & unknown \\
\hline 14.63 & possible benzo isocyanate related compound \\
\hline 15.03 & possible hydroxy benzonitrile related compound \\
\hline 21.23 & penzophenone related compound \\
\hline
\end{tabular}




\section{SI_8: Setup of the abiotic dissolution experiments}

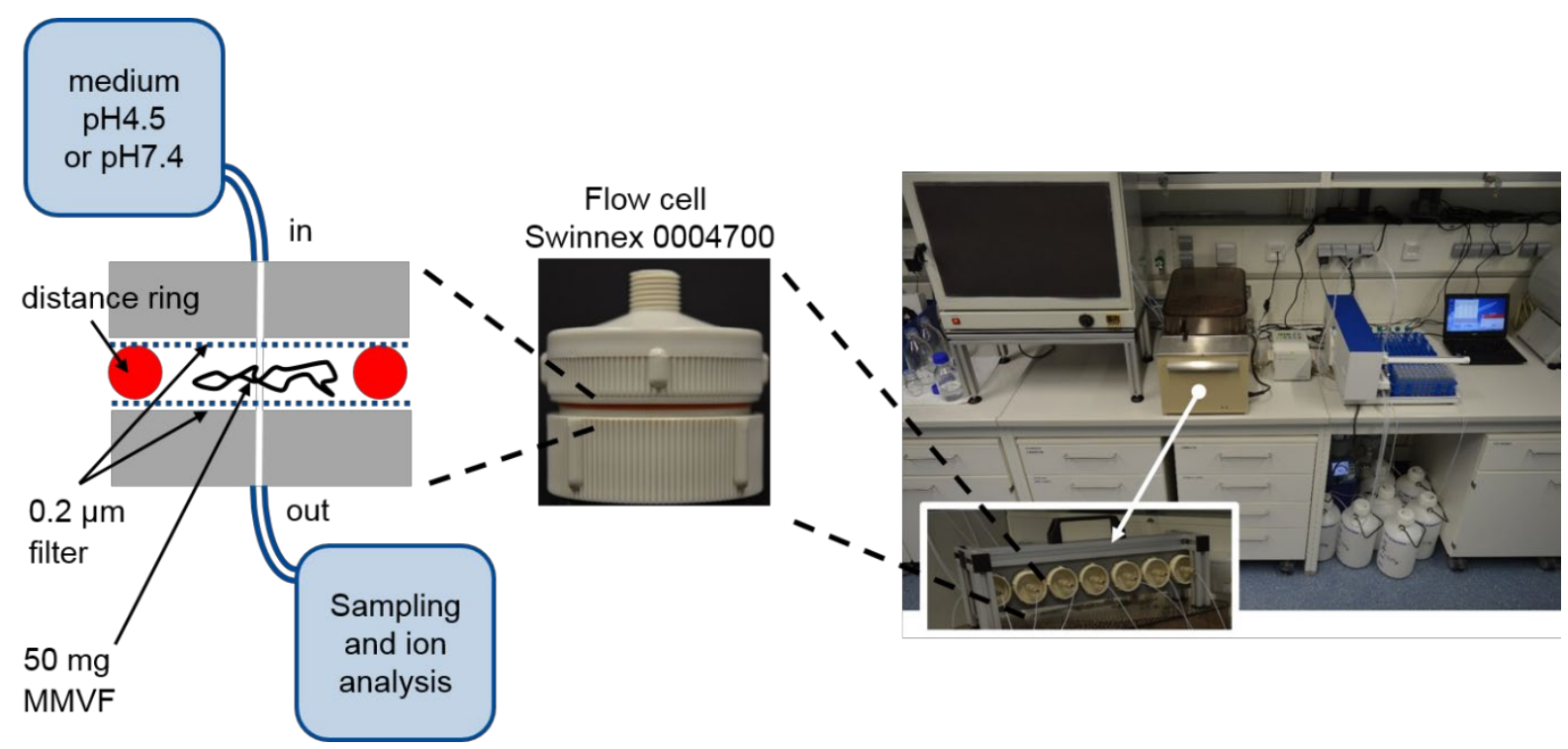

Figure SI_8 The dissolution setup consists of a reservoir, the flow-through cell, a peristaltic pump and an automated sampler. Reproduced with permission from Wohlleben et al, 2017.

\section{Reference}

Wohlleben, W., Waindok, H., Daumann, B., Werle, K., Drum, M., and Egenolf, H. (2017) Composition, respirable fraction and dissolution rate of 24 stone wool MMVF with their binder. Part. Fibre Toxicol. 14(1), 29. 
SI_9: Dissolution kinetics, exemplary results in the pH 4.5 PSF medium
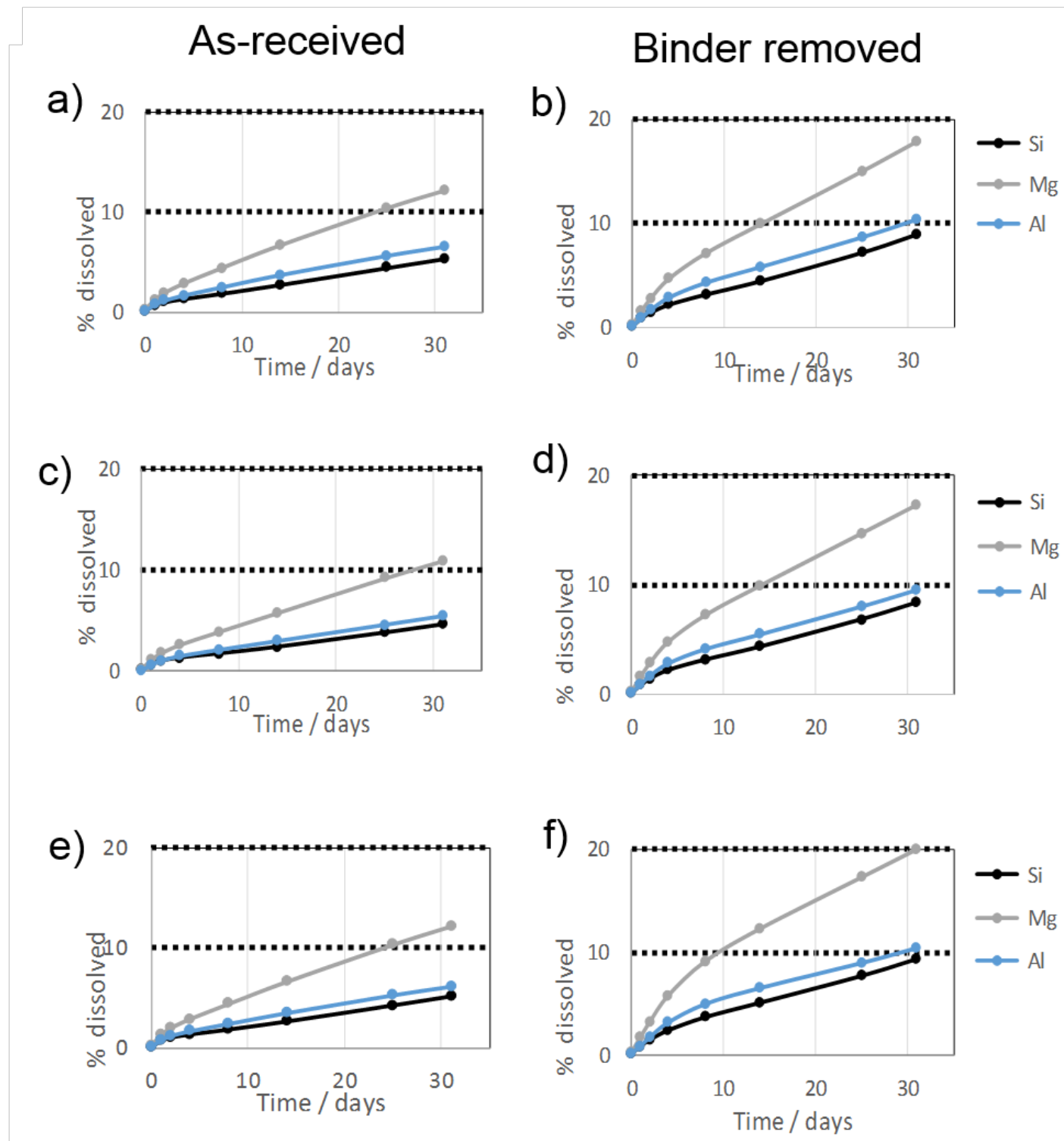

Figure SI_9 Dissolution kinetics, exemplary results in the pH 4.5 PSF medium.

a, c, e) as received

b, d, f) binder removed.
a, b) UK_1
c, d) UK_5
e, f) UK_10

See Figure 2 in main manuscript in for morphologies. 
SI_10: Additional SEM results of fibers as received (no treatment to remove binder), and after pH4.5 PSF dissolution testing (as received with binder)

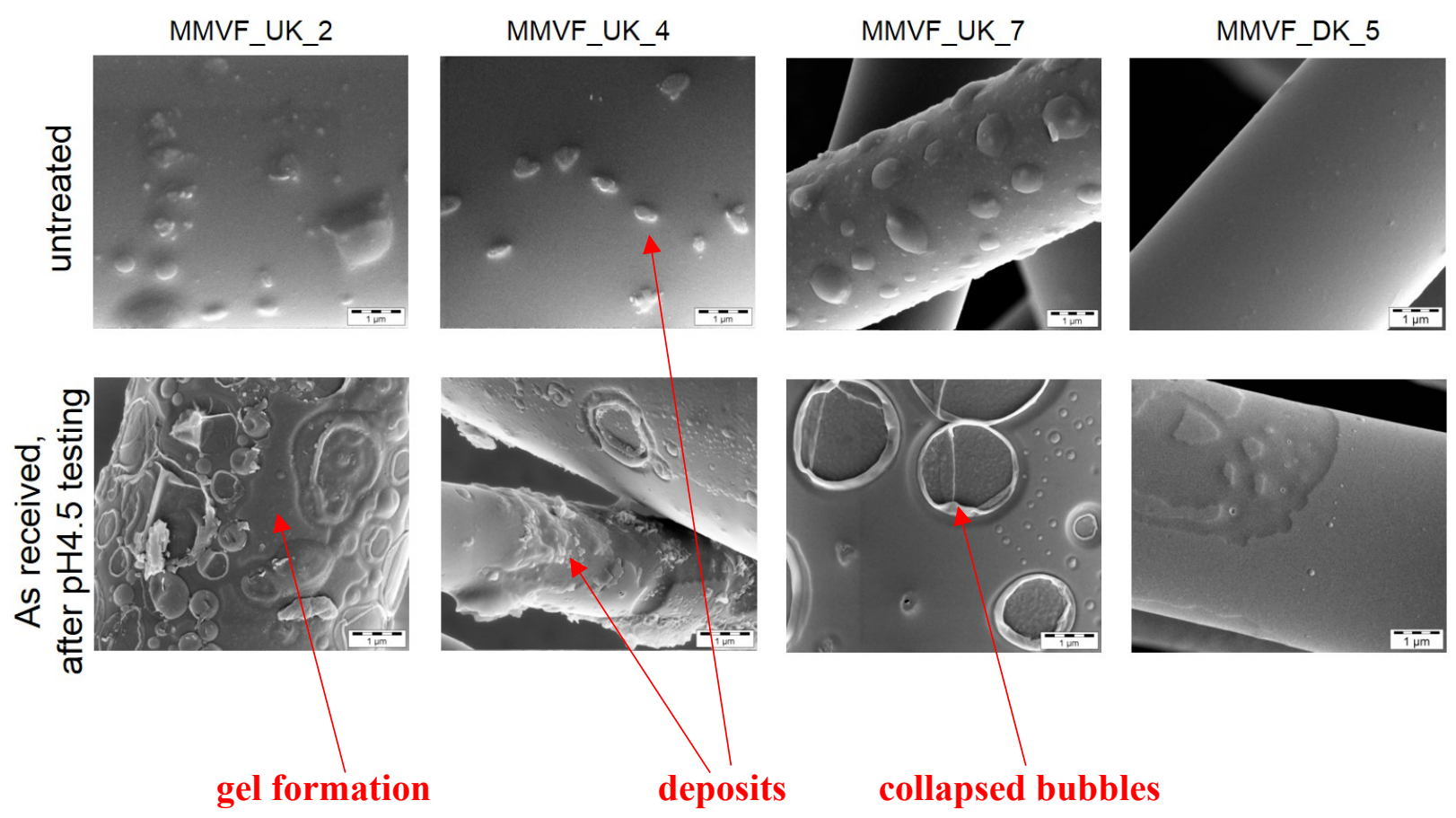

Figure SI_10 Additional SEM results of fibers as received (no treatment to remove binder), and after $\mathrm{pH} 4.5 \mathrm{PSF}$ dissolution testing (as received with binder)

MMVF_UK_2, MMVF_UK_4 and MMVF_UK_7 show deposits of up to $1 \mu \mathrm{m}$ size embedded in the binder. All MMVF_UK show pronounced gel formation and collapsed bubbles after dissolution testing, where MMVF_UK_4 induced deposits inside the membrane to the extent of entirely blocking the flow cell (with binder, not without).

In contrast, MMVF_DK_5 shows only little gel formation in the presence of binder, but also deviated from the UK-sampled materials in oxide composition (Table SI_2) and in the absence of deposits in the initial (untreated) morphology of the binder-coated surface. 


\section{SI_11: Binder coverage on the MMVF_UK_1 fiber surface, detected by SIMS mappings of the fiber surfaces $(50 \mathrm{keV} \mathrm{Bi32+,} 500 \times 500 \mu \mathrm{m}, 256 \times 256$ pixel)}

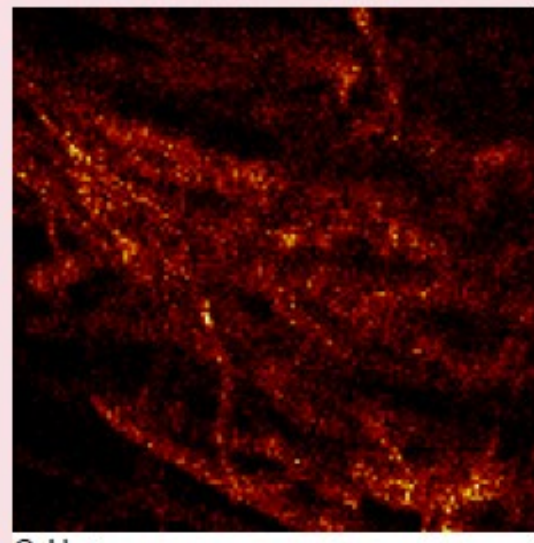

$\mathrm{C}_{7} \mathrm{H}_{7}+$

MC: $24 ; \mathrm{TC}: 4.241 \mathrm{e}+004$

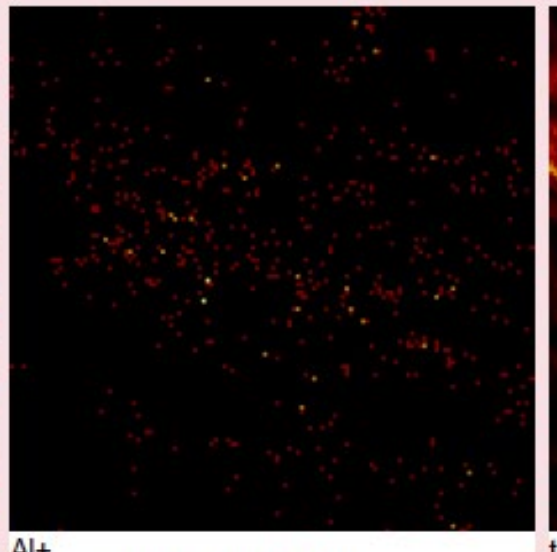

$\mathrm{Al}+$

MC: $4 ;$ TC: $5.590 \mathrm{e}+002$

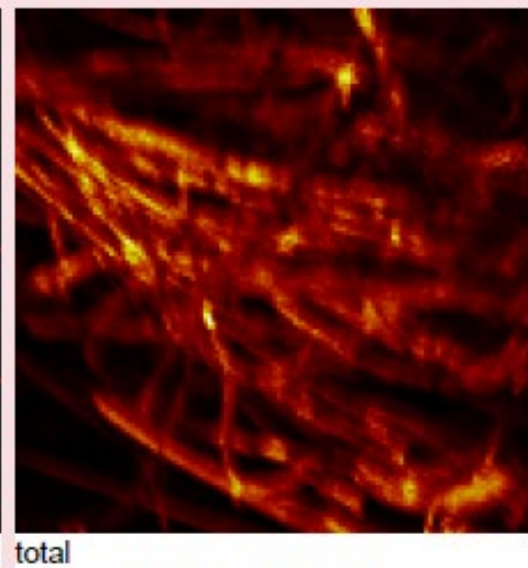

MC: $1549 ;$ TC: $4.489 \mathrm{e}+006$

Figure SI_11 Binder coverage on the MMVF_UK_1 fiber surface, detected by SIMS mappings of the fiber surfaces (50 keV Bi32+, 500x500 $\mu \mathrm{m}, 256 \times 256$ pixel).

Static ToF-SIMS spectra were recorded using a ToF.SIMS 5 spectrometer (IonTOF GmbH, Münster Germany). A pulsed mass-filtered primary ion beam of $50 \mathrm{keV}$ singly charged triple bismuth clusters $\left(\mathrm{Bi}^{2} 2^{+}\right)$was used. This primary ion beam was raster scanned over an area of $500 \mu \mathrm{m} \times 500 \mu \mathrm{m}$ to record spectra and images of positive secondary ions ( $128 \times 128$ pixels). To prevent charging of the sample surface, a low-electron energy flood gun $(\sim 20 \mathrm{eV})$ was used. Mass Resolution was limited by the roughness of the surfaces and was in the range of $\mathrm{M} / \Delta \mathrm{M} \sim 1000$ at $55 \mathrm{u}$. The resulting spectra were analyzed using SurfaceLab 7.0 provided by the instrument manufacturer after mass calibration by using the hydrocarbon peaks $\mathrm{CH}_{3}{ }^{+}(15$ u), $\mathrm{C}_{2} \mathrm{H}_{3}^{+}(27 \mathrm{u}), \mathrm{C}_{3} \mathrm{H}_{5}^{+}(41 \mathrm{u}), \mathrm{C}_{3} \mathrm{H}_{7}^{+}(43 \mathrm{u})$ and $\mathrm{C}_{4} \mathrm{H}_{7}^{+}(55 \mathrm{u})$. 